\title{
A Gemological Study of A COLLECTION OF CHAMELEON DiAMONDS
}

Thomas Hainschwang, Dusan Simic, Emmanuel Fritsch, Branko Deljanin, Sharrie Woodring, and Nicholas DelRe

\begin{abstract}
Chameleon diamonds are among the rarest of gem diamonds. This article reports on a unique collection of 39 chameleon diamonds ranging from 0.29 to $1.93 \mathrm{ct}$, which exhibited temporary changes in color when heated to approximately $150^{\circ} \mathrm{C}$ and, for some, after prolonged storage in the dark (i.e., thermochromic and photochromic color changes, respectively). Most changed from "olive" green to brownish yellow or yellow, although some changed from light yellow to a more intense greenish yellow. The thermochromic and photochromic color change observed in the "olive" green chameleon diamonds is typical of "Classic" chameleons, whereas the solely thermochromic change shown by the light yellow group was the "Reverse" of that seen in Classic chameleon diamonds. The Classic and Reverse groups showed different spectroscopic and UV fluorescence characteristics, but all stones exhibited strong long-lasting phosphorescence after shortwave UV excitation. Hydrogen was identified in all samples by FTIR spectroscopy, and minor $\mathrm{Ni}$ related emissions were detected by photoluminescence spectroscopy in most. Using this combination of reaction to UV radiation and spectroscopic properties, a gemologist can separate chameleon from other green diamonds without unnecessary exposure to heat.
\end{abstract}

T he rarity of chameleon diamonds and their interest for the connoisseur are due to their unusual ability to change color temporarily when heated to about $150^{\circ} \mathrm{C}$ ("thermochromism") or after prolonged storage in the dark ("photochroism"; see Fritsch et al., 1995). The stable color shown by chameleon diamonds is typically grayish yellowish green to grayish greenish yellow ("olive"), while the unstable hue is generally a more intense brownish or orangy yellow to yellow (figures 1 and 2). After heating, the color of a chameleon diamond quickly returns to its stable hue. The color change after storage in the dark is usually not as dramatic as that seen on heating. Some of these chameleons have a stable color reminiscent of "normal" green diamonds. While the green color of these diamonds is caused by exposure to radiation (either naturally or in the laboratory), the mechanism behind chameleon coloration is not yet well understood. Nevertheless, chameleons are among the few green diamonds that can be conclusively identified as natural color, since this behavior cannot be created or enhanced in the laboratory.

Relatively little has been written about chameleon diamonds, and the precise definition of this behavior is not at all clear. For some members of the trade, a temporary photochromic color change must be present for a diamond to be referred to as "chameleon"; in contrast, many publications describe chameleon diamonds as having either a thermochromic (using rather low annealing temperatures) or photochromic temporary color change (Raal, 1969; GIA Diamond Dictionary, 1993; Fritsch et al., 1995).

See end of article for About the Authors and Acknowledgments. Gems \& Gemology, Vol. 41, No. 1, pp. 20-35.

(C) 2005 Gemological Institute of America 

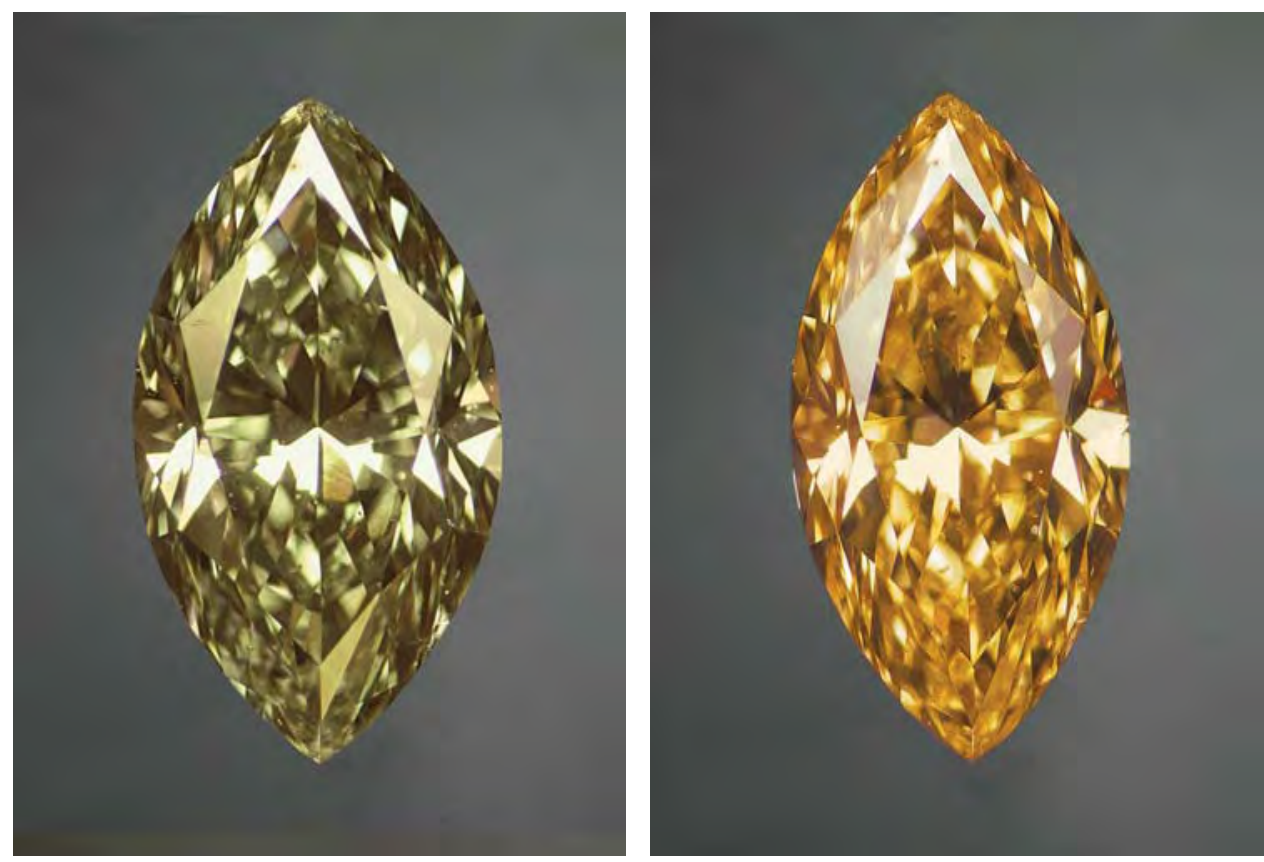

Figure 1. One of the more spectacular chameleon diamonds examined for this study was this $1.01 \mathrm{ct}$ marquise diamond, shown at room temperature (left) and at approximately $150^{\circ} \mathrm{C}$ (right). Photo by T. Hainschwang.

Chameleon diamonds were first documented in 1943 (GIA Diamond Dictionary, 1993), and since then they have been described in several brief reports (see, e.g., Chabert and Reinitz, 2000). Extensive research on a single large chameleon diamond was published by E. Fritsch and colleagues (1995). Most recently, Shigley et al. (2004) reported additional data on chameleon diamonds, including the presence of Ni-related emissions detected by

Figure 2. These images show typical color changes seen in chameleon diamonds of the Classic (top, $0.83 \mathrm{ct}$ ) and Reverse (bottom, 1.09 ct) types. The left images show the stable color, while the unstable color is on the right. Photos by $T$. Hainschwang.
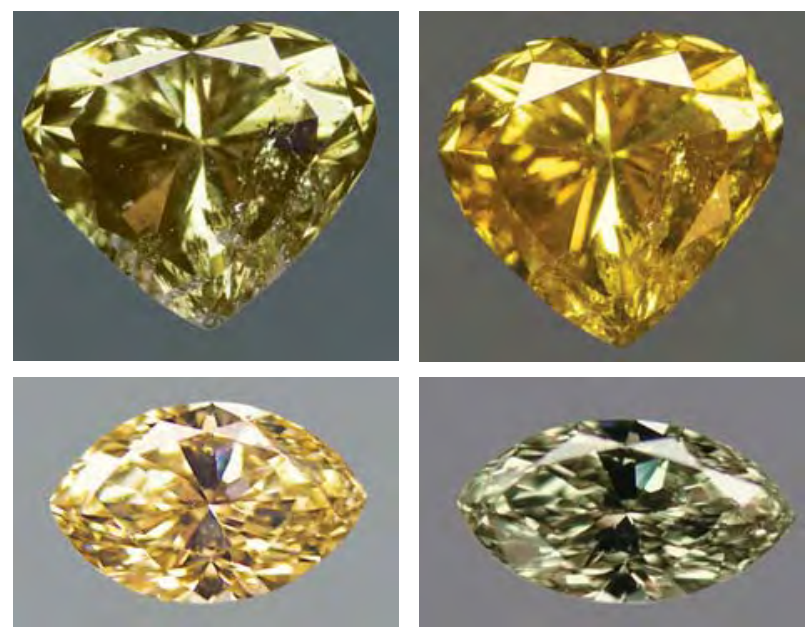

photoluminescence spectroscopy. We believe the present article is the first extensive study of a large number of chameleon diamond samples; it is part of ongoing research by EGL USA on colored diamonds in collaboration with other gemological laboratories and universities worldwide. Some preliminary observations on this collection of chameleon diamonds were published by Deljanin (2004).

\section{MATERIALS AND METHODS}

Thirty-nine chameleon diamonds were included in this study (as described in table 1 and illustrated in figure 3). Unfortunately, the geographic origins of these diamonds are unknown. The stones were purchased between 1987 and 2004: 40\% were obtained in India, 30\% in Antwerp, and 30\% in Tel Aviv. All the diamonds were accompanied by grading reports from either GIA or EGL, which stated that, under certain circumstances, they exhibited a change in color.

The stable color of the chameleon diamonds was graded by the above laboratories, while the unstable color was described by two of the authors (TH and DS). Luminescence to ultraviolet radiation and phosphorescence were observed with a 4-watt UVP UVGL-25 Mineralight Lamp using $254 \mathrm{~nm}$ (short-wave) and $365 \mathrm{~nm}$ (long-wave) excitation. Observations between crossed polarizers were made with a gemological microscope using Leica optics at 10-60× magnification. Color distribution was studied with each stone immersed in methy- 
lene iodide. The change in color was observed using a $6500 \mathrm{~K}$ daylight-equivalent light and a hot plate (range of $40-325^{\circ} \mathrm{C}$ ); the temperature during the heating process was monitored using a thermocouple connected to a digital multimeter. The samples were also cooled in liquid nitrogen to monitor possible color changes induced by low temperature.

We recorded infrared spectra in the range of $6000-400 \mathrm{~cm}^{-1}$ on a Nicolet Nexus 670 FTIR spectrometer, using a diffuse reflectance (DRIFTS) accessory as a beam condenser to facilitate the analysis of small faceted stones, with an accumulation of 100 scans at a resolution of $2-4 \mathrm{~cm}^{-1}$. We recorded pho- toluminescence spectra with the diamonds immersed in liquid nitrogen $\left(\mathrm{T} \approx-196^{\circ} \mathrm{C}\right)$, using an Adamas Advantage SAS2000 system equipped with a $532 \mathrm{~nm}$ semiconductor laser and an Ocean Optics SD2000 spectrometer (resolution $1.5 \mathrm{~nm}$ ) with a 2048-element linear silicon CCD-array detector. Vis-NIR spectra in the range of 400-1000 $\mathrm{nm}$ were collected with the SAS2000 system, using the same spectrometer and detector as described above, with a resolution of $1.5 \mathrm{~nm}$ and 60-250 sample scans. The measurements were performed using an integrating sphere at liquid nitrogen temperature. Also, to monitor changes due to heating, we recorded

TABLE 1. The 39 chameleon diamonds in this study and their changes in color.

\begin{tabular}{|c|c|c|c|c|c|}
\hline $\begin{array}{l}\text { Stone no./ } \\
\text { Grading laba }\end{array}$ & Weight and shape & $\begin{array}{l}\text { Classic or } \\
\text { Reverse group }\end{array}$ & Stable color & Unstable color ${ }^{a}$ & $\begin{array}{l}\text { Magnitude of } \\
\text { color change }\end{array}$ \\
\hline $1.1 / \mathrm{GIA}$ & $0.39 \mathrm{ct}$ round & Classic & $\begin{array}{l}\text { Fancy Dark grayish } \\
\text { greenish yellow }\end{array}$ & $\begin{array}{l}\text { Fancy Intense } \\
\text { orangy yellow }\end{array}$ & Strong \\
\hline $1.2 / \mathrm{GIA}$ & 0.64 ct marquise & Classic & $\begin{array}{l}\text { Fancy Dark brownish } \\
\text { greenish yellow }\end{array}$ & $\begin{array}{l}\text { Fancy Deep brownish } \\
\text { orangy yellow }\end{array}$ & Strong \\
\hline 1.3/GIA & 0.43 ct marquise & Classic & $\begin{array}{l}\text { Fancy Dark grayish } \\
\text { yellowish green }\end{array}$ & $\begin{array}{l}\text { Fancy Deep brownish } \\
\text { orangy yellow }\end{array}$ & Strong \\
\hline 1.4/EGL & $0.63 \mathrm{ct}$ marquise & Classic & Fancy Deep green yellow & $\begin{array}{l}\text { Fancy Deep brownish } \\
\text { greenish yellow }\end{array}$ & Weak \\
\hline $1.5 / \mathrm{GIA}$ & 1.60 ct pear & Classic & Fancy Dark yellowish brown & $\begin{array}{l}\text { Fancy Deep brownish } \\
\text { orangy yellow }\end{array}$ & Strong \\
\hline 1.6/GIA & 0.46 ct pear & Classic & $\begin{array}{l}\text { Fancy Dark grayish yellowish } \\
\text { green }\end{array}$ & $\begin{array}{l}\text { Fancy Intense orangy } \\
\text { yellow }\end{array}$ & Strong \\
\hline 1.7/EGL & $0.83 \mathrm{ct}$ heart & Classic & $\begin{array}{l}\text { Fancy Deep grayish } \\
\text { yellowish green }\end{array}$ & $\begin{array}{l}\text { Fancy Intense orangy } \\
\text { yellow }\end{array}$ & Strong \\
\hline $1.8 / \mathrm{GIA}$ & 1.75 ct cushion & Classic & $\begin{array}{l}\text { Fancy Dark grayish } \\
\text { yellowish green }\end{array}$ & Fancy greenish yellow & Weak \\
\hline $1.9 / \mathrm{GIA}$ & $0.67 \mathrm{ct}$ oval & Classic & $\begin{array}{l}\text { Fancy Dark grayish } \\
\text { yellowish green }\end{array}$ & Fancy Intense yellow & Strong \\
\hline $2.1 / \mathrm{GIA}$ & 1.93 ct marquise & Classic & $\begin{array}{l}\text { Fancy Deep brownish } \\
\text { greenish yellow }\end{array}$ & $\begin{array}{l}\text { Fancy Deep brownish } \\
\text { orangy yellow }\end{array}$ & Strong \\
\hline 2.2/GIA & 0.72 ct marquise & Classic & $\begin{array}{l}\text { Fancy brownish } \\
\text { greenish yellow }\end{array}$ & $\begin{array}{l}\text { Fancy Deep orangy } \\
\text { brown yellow }\end{array}$ & Strong \\
\hline 2.3/GIA & 0.58 ct marquise & Classic & $\begin{array}{l}\text { Fancy grayish greenish } \\
\text { brown yellow }\end{array}$ & $\begin{array}{l}\text { Fancy Deep brownish } \\
\text { orangy yellow }\end{array}$ & Strong \\
\hline 2.4/GIA & $0.81 \mathrm{ct}$ heart & Classic & $\begin{array}{l}\text { Fancy Deep brownish } \\
\text { greenish yellow }\end{array}$ & $\begin{array}{l}\text { Fancy Deep brownish } \\
\text { orangy yellow }\end{array}$ & Strong \\
\hline 2.5/GIA & 0.48 ct marquise & Classic & Fancy brownish yellow & $\begin{array}{l}\text { Fancy Intense yellowish } \\
\text { orange }\end{array}$ & Strong \\
\hline 2.6/GIA & 0.29 ct marquise & Classic & $\begin{array}{l}\text { Fancy brownish greenish } \\
\text { yellow }\end{array}$ & $\begin{array}{l}\text { Fancy Intense orangy } \\
\text { yellow }\end{array}$ & Strong \\
\hline 2.7/GIA & $0.57 \mathrm{ct}$ heart & Classic & $\begin{array}{l}\text { Fancy grayish greenish } \\
\text { yellow }\end{array}$ & Fancy brownish yellow & Strong \\
\hline 2.8/EGL & $0.46 \mathrm{ct}$ round & Classic & $\begin{array}{l}\text { Fancy Deep brownish } \\
\text { greenish yellow }\end{array}$ & $\begin{array}{l}\text { Fancy Deep brownish } \\
\text { orangy yellow }\end{array}$ & Strong \\
\hline 2.9/EGL & $0.52 \mathrm{ct}$ round & Reverse & Fancy Light brownish yellow & Fancy greenish yellow & Moderate \\
\hline
\end{tabular}

aDescriptions of the unstable colors for all of the diamonds were determined by the authors. Note that, presently, GIA only recognizes the Classic type (and not the Reverse type) as a chameleon diamond. 
spectra at room temperature as well as with some stones heated to approximately $325^{\circ} \mathrm{C}$; the higher temperature was used to assure that the diamond was in its unstable color state during the accumulation of the spectrum.

In addition to the 39 diamonds included in the chameleon collection, one additional chameleon diamond was analyzed (box A); the sample, referenced as TH-A1, was first described by Hainschwang (2001). An FTIR spectrum of a hydrogen-rich chameleon diamond, which was not part of the collection, called "TH-cham1," is included to compare the strength of color change with hydrogen content.

\section{RESULTS}

Color Description. Two different stable-color groups were observed in the chameleon diamonds (see figure 3, top):

1. Green with a gray, brown, or yellow color component ("olive"); or yellow with green, brown, or gray modifying colors. These are referred to hereafter as "Classic."

2. Light yellow with typically a greenish, grayish, or brownish component. These are referred to as "Reverse."

\begin{tabular}{|c|c|c|c|c|c|}
\hline $\begin{array}{l}\text { Stone no./ } \\
\text { Grading Lab }\end{array}$ & Weight and shape & $\begin{array}{l}\text { Classic or } \\
\text { Reverse group }\end{array}$ & Stable color & Unstable color & $\begin{array}{l}\text { Magnitude of } \\
\text { color change }\end{array}$ \\
\hline 3.2/GIA & 1.52 ct oval & Classic & Fancy grayish yellowish green & Fancy Deep brownish yellow & v Strong \\
\hline 3.3/GIA & 0.47 ct marquise & Classic & $\begin{array}{l}\text { Fancy grayish yellowish } \\
\text { green }\end{array}$ & Fancy brownish yellow & Strong \\
\hline $3.4 / \mathrm{GIA}$ & 0.58 ct marquise & Classic & Fancy Deep brownish yellow & $\begin{array}{l}\text { Fancy Deep brownish } \\
\text { yellow }\end{array}$ & Strong \\
\hline 3.5/GIA & $1.01 \mathrm{ct}$ marquise & Classic & $\begin{array}{l}\text { Fancy grayish yellowish } \\
\text { green }\end{array}$ & Fancy Intense yellow & Strong \\
\hline 3.6/GIA & 1.54 ct marquise & Classic & Fancy gray yellowish green & Fancy grayish yellow & $\begin{array}{l}\text { Moderate to } \\
\text { strong }\end{array}$ \\
\hline 3.7/GIA & 0.41 ct round & Classic & Fancy Dark greenish gray & Fancy Intense yellow & Strong \\
\hline 3.8/GIA & 0.29 ct round & Classic & Fancy Dark greenish gray & $\begin{array}{l}\text { Fancy Deep brownish } \\
\text { yellow }\end{array}$ & Strong \\
\hline 3.9/GIA & $0.47 \mathrm{ct}$ round & Classic & $\begin{array}{l}\text { Fancy Dark grayish } \\
\text { yellowish green }\end{array}$ & Fancy Intense yellow & Strong \\
\hline 3.10/GIA & 0.47 ct round & Classic & $\begin{array}{l}\text { Fancy grayish yellowish } \\
\text { green }\end{array}$ & Fancy Intense yellow & Strong \\
\hline $3.11 / \mathrm{GIA}$ & $0.51 \mathrm{ct}$ round & Classic & Fancy gray greenish yellow & Fancy greenish yellow & Moderate \\
\hline $3.12 / \mathrm{GIA}$ & $0.39 \mathrm{ct}$ round & Classic & $\begin{array}{l}\text { Fancy yellowish-yellowish } \\
\text { green }\end{array}$ & Fancy orangy yellow & Strong \\
\hline $4.2 / \mathrm{GIA}$ & $0.47 \mathrm{ct}$ round & Classic & Fancy Light yellow & Fancy greenish yellow & Weak \\
\hline 4.3/EGL & $0.57 \mathrm{ct}$ round & Reverse & Light grayish greenish yellow & Fancy yellow-green & Moderate \\
\hline $4.4 / \mathrm{GIA}$ & $0.56 \mathrm{ct}$ round & Classic & $\begin{array}{l}\text { Fancy Light grayish greenish } \\
\text { yellow }\end{array}$ & Fancy brownish yellow & Weak \\
\hline 4.5/EGL & $0.59 \mathrm{ct}$ round & Reverse & Very Light yellow & $\begin{array}{l}\text { Fancy Light greenish } \\
\text { yellow }\end{array}$ & $\begin{array}{l}\text { Moderate to } \\
\text { strong }\end{array}$ \\
\hline 4.7/EGL & 0.51 ct marquise & Reverse & Very Light grayish yellow & Fancy yellow-green & Strong \\
\hline 4.8/EGL & 0.46 ct marquise & Reverse & Light grayish greenish yellow & Fancy Light yellow-green & $\begin{array}{l}\text { Moderate to } \\
\text { strong }\end{array}$ \\
\hline 4.9/EGL & 0.58 ct marquise & Reverse & Light brownish yellow & Fancy greenish yellow & $\begin{array}{l}\text { Moderate to } \\
\text { strong }\end{array}$ \\
\hline 4.10/EGL & 0.47 ct marquise & Reverse & Light yellow (U-V) & $\begin{array}{l}\text { Fancy Light greenish } \\
\text { yellow }\end{array}$ & Moderate \\
\hline 4.11/GIA & 0.80 ct marquise & Classic & $\begin{array}{l}\text { Fancy brownish greenish } \\
\text { yellow }\end{array}$ & $\begin{array}{l}\text { Fancy Intense orangy } \\
\text { yellow }\end{array}$ & Strong \\
\hline 4.12/EGL & 0.36 ct marquise & Reverse & Light yellow (U-V) & $\begin{array}{l}\text { Fancy Light greenish } \\
\text { yellow }\end{array}$ & Moderate \\
\hline
\end{tabular}




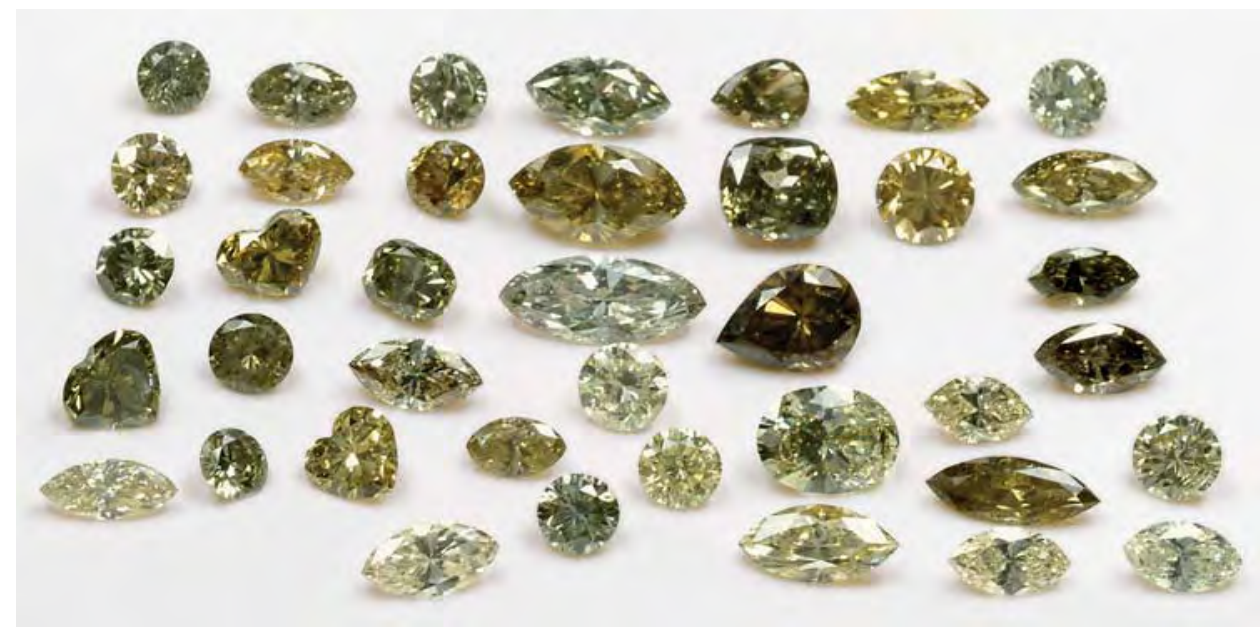

Figure 3. The collection of 39 chameleon diamonds (0.29 to $1.93 \mathrm{ct}$ )

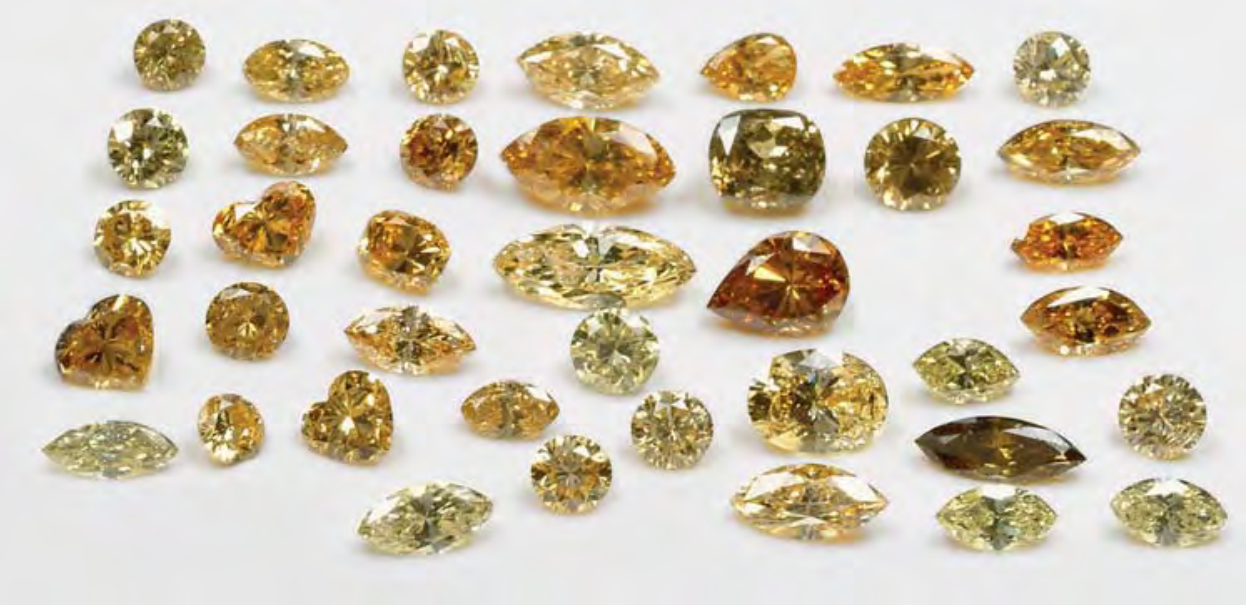
is shown at room temperature (top) and when heated to $150^{\circ} \mathrm{C}$ (bottom). Photos by Julia Kagantsova, EGL.

The Classic group of chameleons $(31$ of the 39 diamonds) exhibited a distinct change in color when heated (figure 3, bottom). The unstable color varied from saturated brown-yellow to orange-yellow to yellow. The same change of color also was observed after prolonged storage in the dark for all except four stones, but it was not nearly as pronounced as the change induced by heating. Usually a couple of hours in darkness was sufficient to induce the color change. Cooling to liquid nitrogen temperature did not provoke a color change.

The Reverse group (8 of the 39 diamonds) differed from the first group in that heating induced only a weak-to-moderate change to a more saturated and greener color (again, see figure 3, bottom). Storage in the dark, even for days, did not provoke a change in color. As in the Classic chameleons, the color was not influenced by cooling to liquid nitrogen temperature $\left(-196^{\circ} \mathrm{C}\right)$. We use the term Reverse for such chameleon diamonds, because their yellow-to-yellowish green color change is almost the opposite of the green-to-yellow change seen in typical chameleon diamonds.
The change in color due to heating began at approximately $100-120^{\circ} \mathrm{C}$ in both groups. For the majority of the stones, the unstable color was most intense between 120 and $140^{\circ} \mathrm{C}$. Although the diamonds were heated up to $300^{\circ} \mathrm{C}$, no further changes in color were observed above about $140^{\circ} \mathrm{C}$. At this temperature, a complete change in color could be induced within a few seconds.

Color Distribution. The color in most of the chameleon diamonds was evenly distributed; however, a few of the samples from the Classic group showed very slight patchy (irregular) color zoning. One diamond, also from the Classic group, exhibited very distinct yellow-brown banding (figure 4).

Anomalous Double Refraction. Between crossed polarizing filters, no characteristic pattern was seen. Some strain was observed in all samples, evident as interference colors of various intensity, and was mainly associated with inclusions. Deformationrelated extinction patterns along octahedral slip planes (as typically seen in many brown to brownish 
yellow-green diamonds) were observed in only a few samples, and were localized and very indistinct.

Reaction to UV Radiation. All samples exhibited characteristic long- and short-wave UV fluorescence. There were basically two types of responses:

1. Classic group: chalky white to chalky yellow to yellow, stronger to long-wave than to short-wave UV (figure 5)

2. Reverse group: chalky blue to blue to long-wave, and weaker chalky blue to yellow to short-wave UV (figure 6)

Most of the diamonds displayed moderate to strong luminescence to long-wave UV radiation, with a weak to moderate response to short-wave UV. The most interesting feature was that all stones exhibited persistent phosphorescence, more distinctly to short-wave than to long-wave UV. The phosphorescent color was yellow for all samples, but its strength and decay time varied considerably: Light yellow stones of the Reverse group that exhibited blue fluorescence had much weaker and shorter phosphorescence than the Classic-group diamonds that exhibited chalky white to yellow luminescence (again, see figures 5 and 6). Some of the diamonds of the Classic group emitted a faint, but still eye-visi-

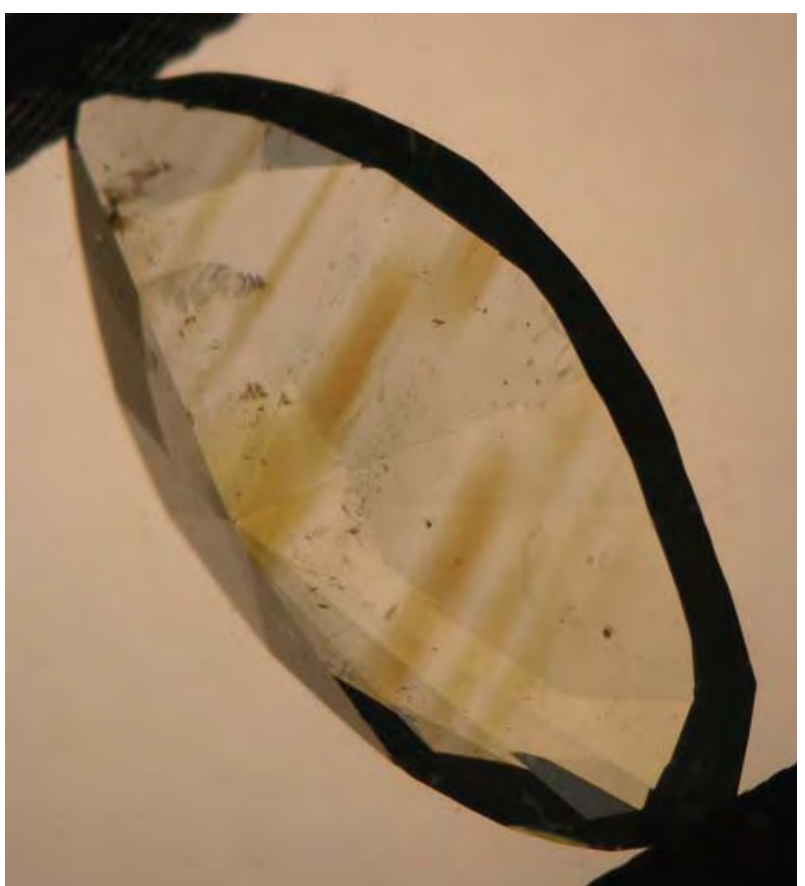

Figure 4. This $1.93 \mathrm{ct}$ chameleon diamond from the Classic group was the only sample that showed distinct color banding. Photo by T. Hainschwang.

ble, yellow glow over one hour later. In contrast, the phosphorescence of the Reverse group diamonds lasted just a few seconds to a few minutes. A Reverse-type diamond (TH-A1) analyzed prior to

\section{BOX A: AN Unusual ReVerse ChameleON Diamond}

What is believed to be the first report of a "low-temperature" (i.e., below $200^{\circ} \mathrm{C}$ ) thermochromic color change observed in a very high-nitrogen and highhydrogen yellow diamond exhibiting Reverse chameleon behavior was published by Hainschwang (2001). The 1.09 ct marquise cut diamond, here referred to as TH-A1 (figure 2, bottom; figure 8, orange trace), exhibited a Vis-NIR spectrum with several hydrogen-related peaks-notably at 425, 440, $452,462,474,545$, and $563 \mathrm{~nm}$ - similar to the spectrum shown in figure 11 (green trace). The Reverse chameleon diamonds included in the present article exhibit only a few of these absorptions, and they commonly show distinctly less IR-active hydrogen. Nevertheless, the color change shown by those diamonds is as strong, and in some stones stronger, than exhibited by sample TH-A1. An interesting characteristic of this diamond is that the luminescence and phosphorescence behavior change on heating (table A-1). Further research will be needed before the mechanism that produces these phenomena can be understood.

TABLE A-1. Variations in the emissions excited by UV radiation observed in sample TH-A1.

\begin{tabular}{|c|c|c|c|c|}
\hline \multirow[t]{2}{*}{ Luminescence } & \multicolumn{2}{|c|}{ Long-wave UV } & \multicolumn{2}{|c|}{ Short-wave UV } \\
\hline & Room temperature & Hot $\left(\sim 200^{\circ} \mathrm{C}\right)$ & Room temperature & Hot $\left(\sim 200^{\circ} \mathrm{C}\right)$ \\
\hline $\begin{array}{l}\text { Fluorescence } \\
\text { Phosphorescence }\end{array}$ & $\begin{array}{l}\text { Violetish blue } \\
\text { Weak yellow }\end{array}$ & $\begin{array}{l}\text { Zoned blue and yellow } \\
\text { Distinct blue }\end{array}$ & $\begin{array}{l}\text { Chalky bluish yellow } \\
\text { Distinct yellow }\end{array}$ & $\begin{array}{l}\text { Blue with yellow zones } \\
\text { Weak blue }\end{array}$ \\
\hline
\end{tabular}




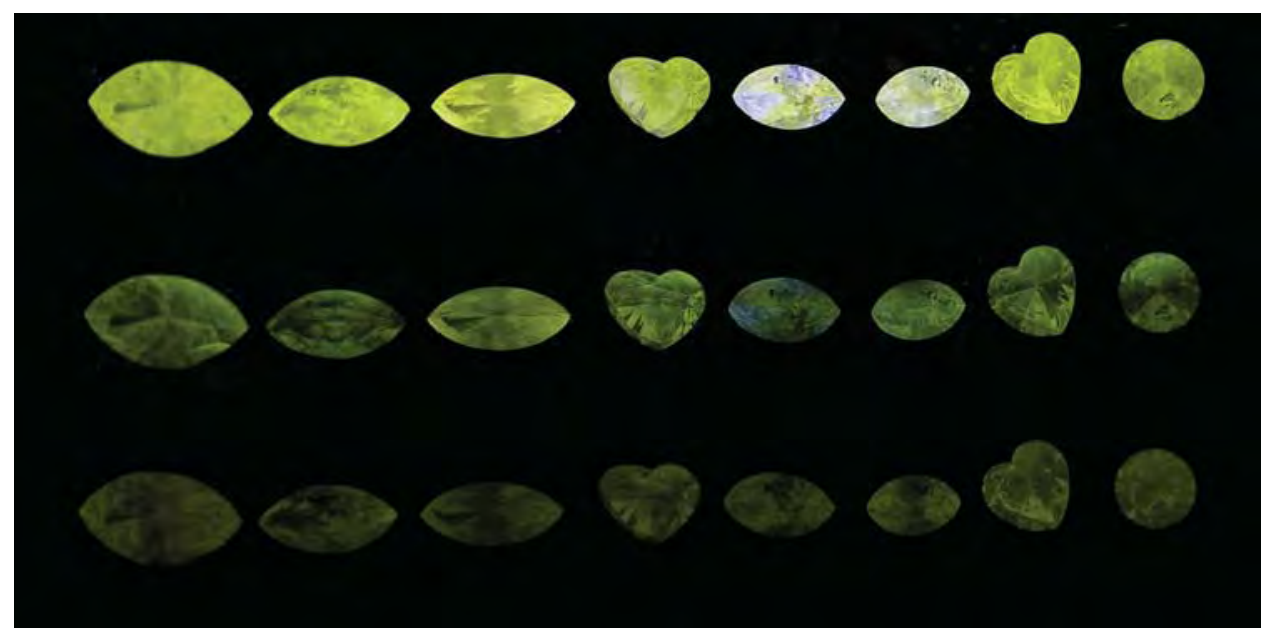

Figure 5. These samples (nos. 2.1-2.8, from left to right) demonstrate the appearance of Classic chameleon diamonds when exposed to long-wave UV (top row), short-wave UV (center row), and after the UV source was turned off (bottom row). Composite photo by T. Hainschwang.

this study exhibited a remarkable inversion of luminescence and phosphorescence behavior when heated (box A).

Infrared Spectroscopy. The infrared spectra also help distinguish the two groups of chameleon diamonds:

1. Classic group: low to moderate concentrations of nitrogen, mainly A aggregates (rarely $\mathrm{A} \sim \mathrm{B}$ ), and low-to-moderate hydrogen content (figure 7)

2. Reverse group: high to very high concentrations of nitrogen, mainly in the form of $\mathrm{B}$ aggregates (very rarely $\mathrm{B}<\mathrm{A}$ ), and low-to-high hydrogen content (figure 8)

Classic Group. The low-to-moderate nitrogen, type IaA chameleon spectra (Classic group) are characterized by hydrogen-related absorptions at 4496,4167 , $3235,3186,3181,3160,3143,3138,3107,2786$, and $1405 \mathrm{~cm}^{-1}$ (not all of these are visible in figure 7). A peak present in most Classic chameleons at 1434-1428 $\mathrm{cm}^{-1}$ (again, see figure 7) was relatively weak and broad (FWHM $\left.25-35 \mathrm{~cm}^{-1}\right)$. This absorption was in no way related to the intensity of a platelet peak at $1358-1380 \mathrm{~cm}^{-1}$, as described by Woods (1986; see figure 9). Most of the stones showed a weak type Ib character, which was visible as some hydrogen-related peaks such as the 3143 $\mathrm{cm}^{-1}$ line (Woods and Collins, 1983), a shoulder at $1135 \mathrm{~cm}^{-1}$, and in a few stones as very weak sharp peaks at $1344 \mathrm{~cm}^{-1}$.

In addition to the hydrogen- and nitrogen-related features, the Classic chameleon diamonds exhibited absorptions at $1548-1544 \mathrm{~cm}^{-1}$ and $1590-1577 \mathrm{~cm}^{-1}$, plus a weak peak at $1464 \mathrm{~cm}^{-1}$.

Reverse Group. The high-nitrogen, mostly type IaB chameleon spectra (Reverse group) also exhibited hydrogen-related features: sharp peaks at 4496,4167 , $3236,3107,3055,2982,2813$ and $2786 \mathrm{~cm}^{-1}$ were observed (figure 8; peaks at 3055, 2982 and 2813 are too small to be seen at this scale). However, the Reverse chameleon diamonds lacked any features assigned to a type $\mathrm{Ib}$ character. The peak at $1430 \mathrm{~cm}^{-1}$ was found to be asymmetric and relatively strong and sharp (FWHM $\sim 8-9 \mathrm{~cm}^{-1}$ ), and it could be directly correlated with the intensity of the platelet peak (figure 9) as documented by Woods (1986).

The N-related absorptions in the one-phonon region were truncated in the Reverse chameleon spectra (see figure 8), so the strengths of the 1282 and $1175 \mathrm{~cm}^{-1}$ absorptions that indicate the relative amounts of A- and B-aggregates could not be compared. Consequently, to determine which aggre-

Figure 6. These samples (nos. 4.7-4.10, from left to right) demonstrate the appearance of Reverse chameleon diamonds when exposed to long-wave UV (top row), short-wave UV (center row), and after the $U V$ was turned off (bottom row). Composite photo by T. Hainschwang.

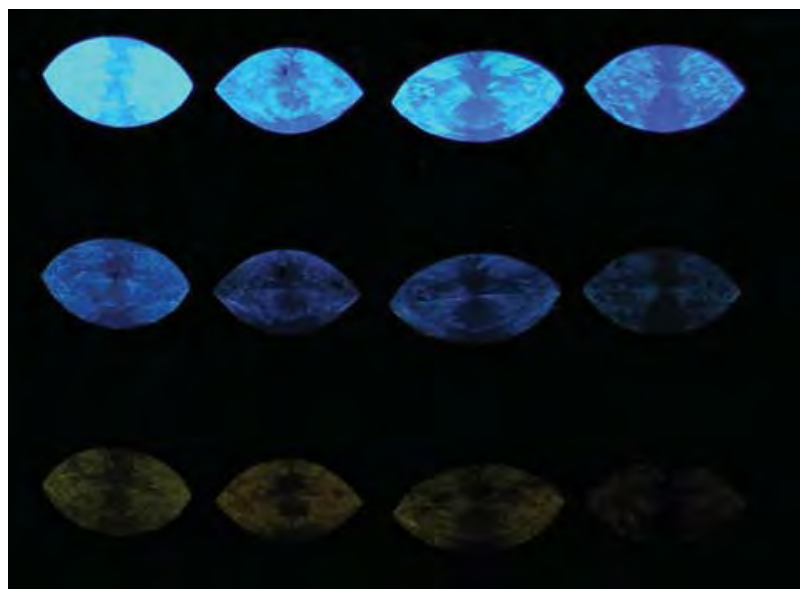




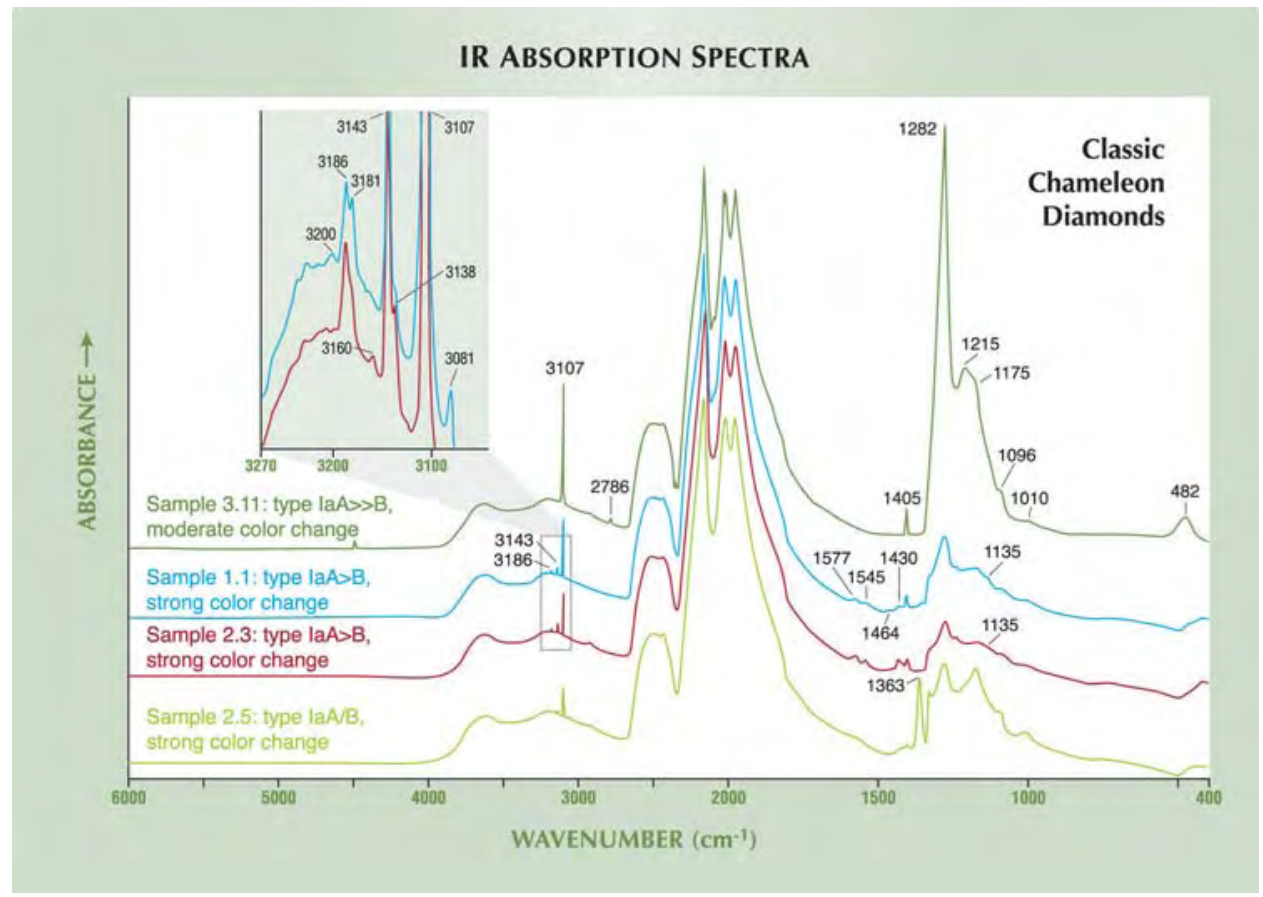

Figure 7. The infrared spectra of Classic chameleon diamonds show variable hydrogen and nitrogen contents. The spectrum of sample 2.5 is the exception, since strong $B$-aggregate absorption is very rare in such diamonds. The spectra show that the quantity of IR-active hydrogen does not correlate to the intensity of the color change. The hydrogen-related absorptions indicating $a$ type Ib character are shown in the inset. The spectra have been shifted vertically for clarity.

gates were dominant, related peaks at $1010 \mathrm{~cm}^{-1}(\mathrm{~B}-$ aggregates) and $482 \mathrm{~cm}^{-1}$ (A-aggregates) were compared. In these stones, the $482 \mathrm{~cm}^{-1}$ peak was typically very weak or absent, whereas the $1010 \mathrm{~cm}^{-1}$ feature was always strong; it thus could be concluded that the Reverse chameleon diamonds are predominantly type IaB diamonds.

Several absorptions between 1577 and 1450 $\mathrm{cm}^{-1}$ were noted in spectra of certain Reverse group diamonds (i.e., at 1577, 1554, 1551, 1546, $1543,1526,1523,1521,1518,1508,1500,1498$, 1490,1473 , and $\left.1450 \mathrm{~cm}^{-1}\right)$. None of the studied chameleon diamonds exhibited deformation-related amber center absorptions (i.e., with main features in the range of $4165-4065 \mathrm{~cm}^{-1}$; DuPreez, 1965 and Hainschwang, 2003).

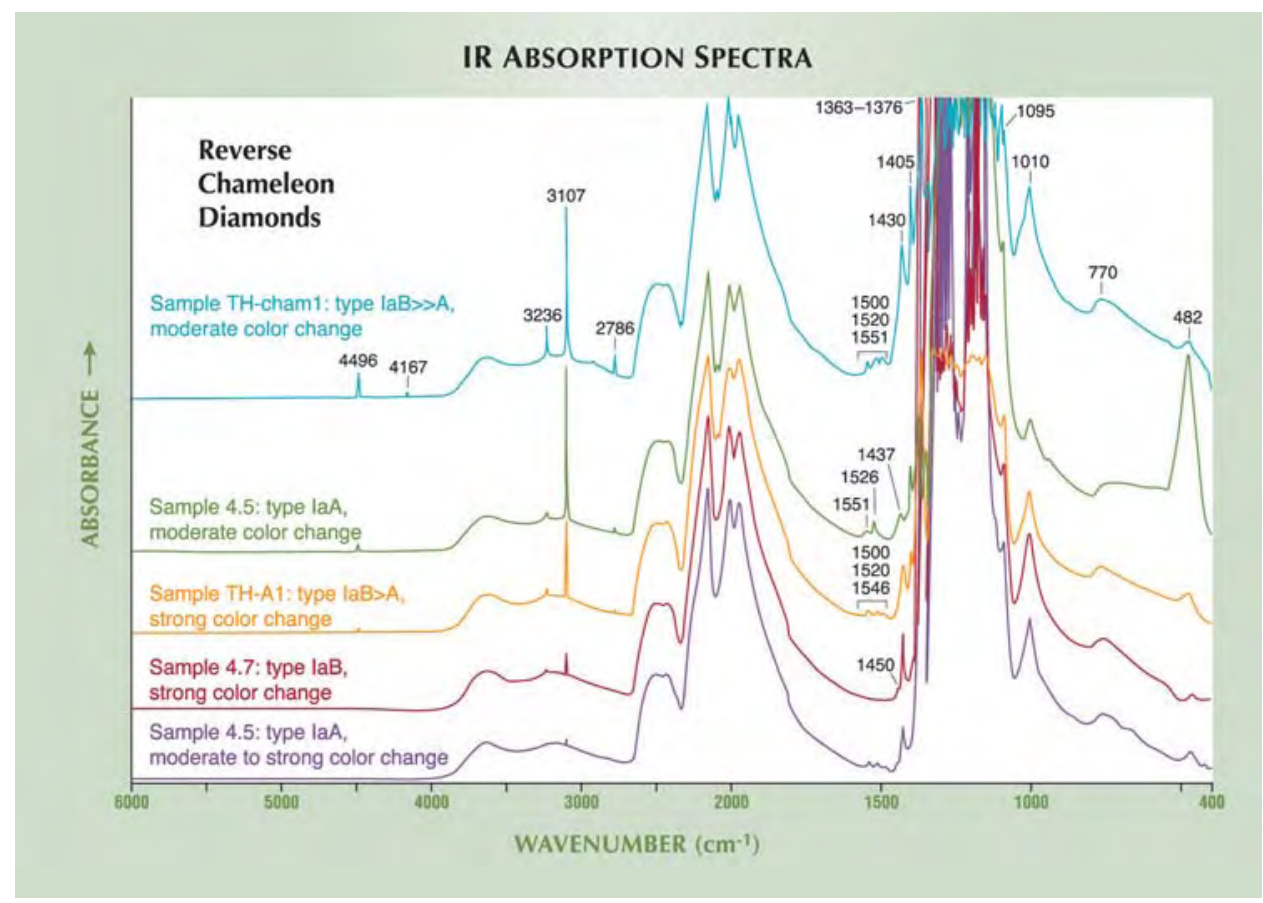

Figure 8. The infrared spectra of Reversechameleon diamonds show similar features, except for a more variable hydrogen content. The spectrum of sample 4.5 is the exception, since strong A-aggregate absorption is very rare in such diamonds. The spectra show that the quantity of IR-active hydrogen does not correlate to the intensity of the color change. The spectra have been shifted vertically for clarity. 


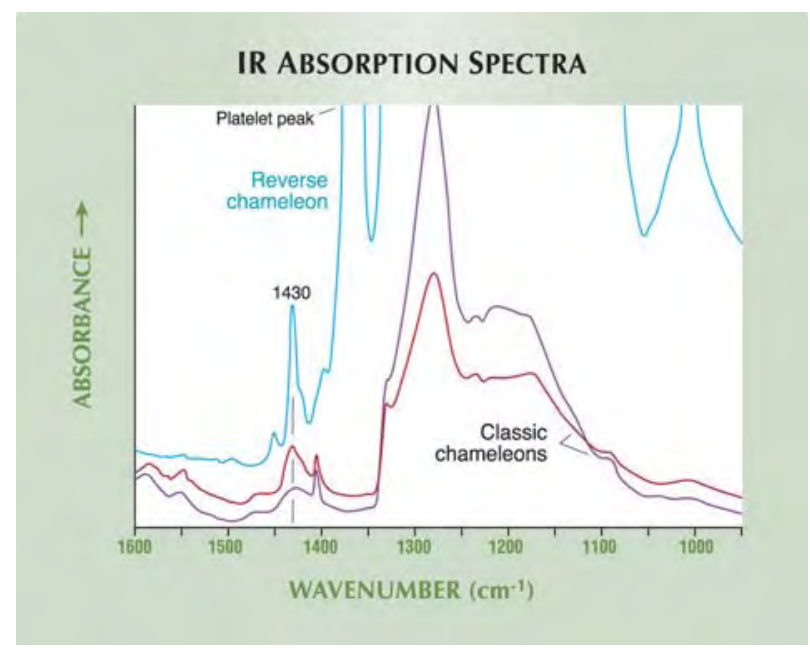

Figure 9. The $1430 \mathrm{~cm}^{-1}$ absorption is present in the IR spectra of both Classic and Reverse chameleon diamonds. However, the specific appearance of this absorption and absence of a platelet peak in the Classic chameleon diamonds indicates that the 1430 $\mathrm{cm}^{-1}$ peak in those diamonds has a different origin than the platelet-related $1430 \mathrm{~cm}^{-1}$ feature in the Reverse chameleons.

Vis-NIR Spectroscopy. As was the case for standard gemological testing and FTIR spectroscopy, the two groups of chameleon diamonds also showed different absorption spectra in the visible to nearinfrared range.

Figure 11. These Vis-NIR spectra compare the absorption features of a yellow-orange type Ib/aA diamond colored by the $480 \mathrm{~nm}$ band, a grayish yellow-green $H$-rich diamond, and a Classic chameleon diamond showing the $480 \mathrm{~nm}$ band and H-related features. The spectra have been shifted vertically for clarity.

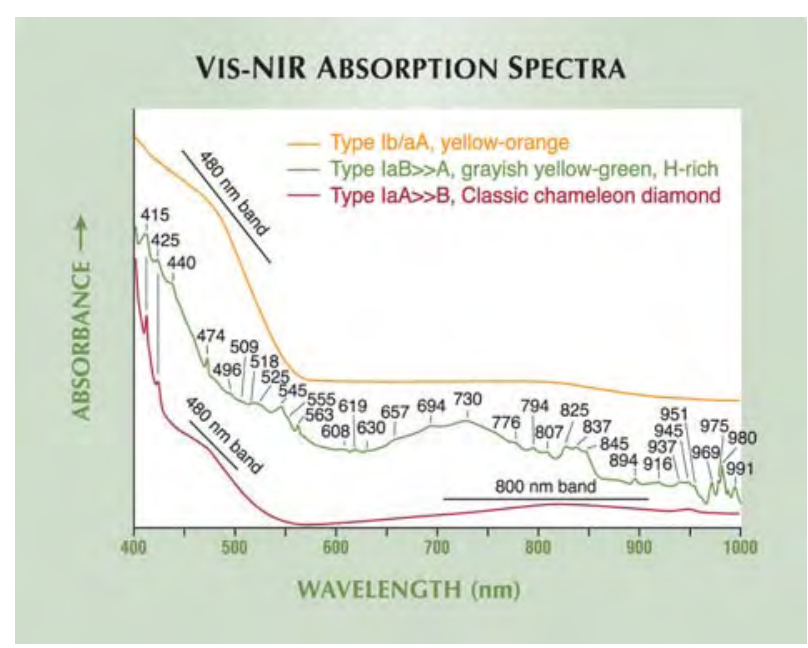

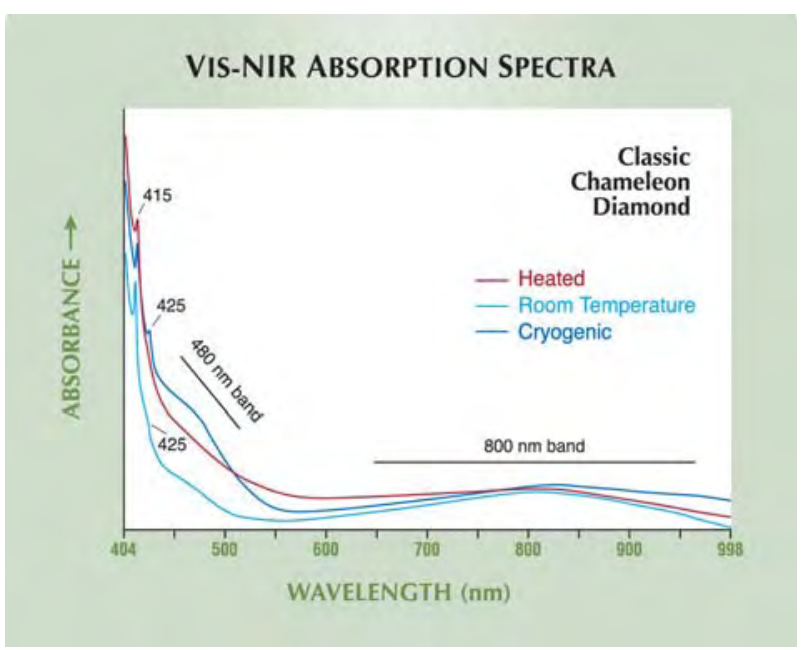

Figure 10. These Vis-NIR spectra were recorded for a Classic-group chameleon diamond at room temperature, when cooled with liquid nitrogen, and when heated. The characteristic $425 \mathrm{~nm}$ band and the broad features at 480 and $800 \mathrm{~nm}$ became less pronounced when the diamond was heated. The spectra have been shifted vertically for clarity.

Classic Group. Diamonds from this group showed absent or usually weak absorption at $415 \mathrm{~nm}$ (N3), weak absorption at $425 \mathrm{~nm}$, a weak to distinct broad band at $480 \mathrm{~nm}$, and a very broad band centered at $775-825 \mathrm{~nm}$ (figure 10).

Figure 12. These Vis-NIR spectra of a Reverse-group chameleon diamond were recorded at room temperature and when heated. Heating weakened the characteristic peaks between 415 and $478 \mathrm{~nm}$ and the broad band centered at 750-800 nm. The spectra have been shifted vertically for clarity.

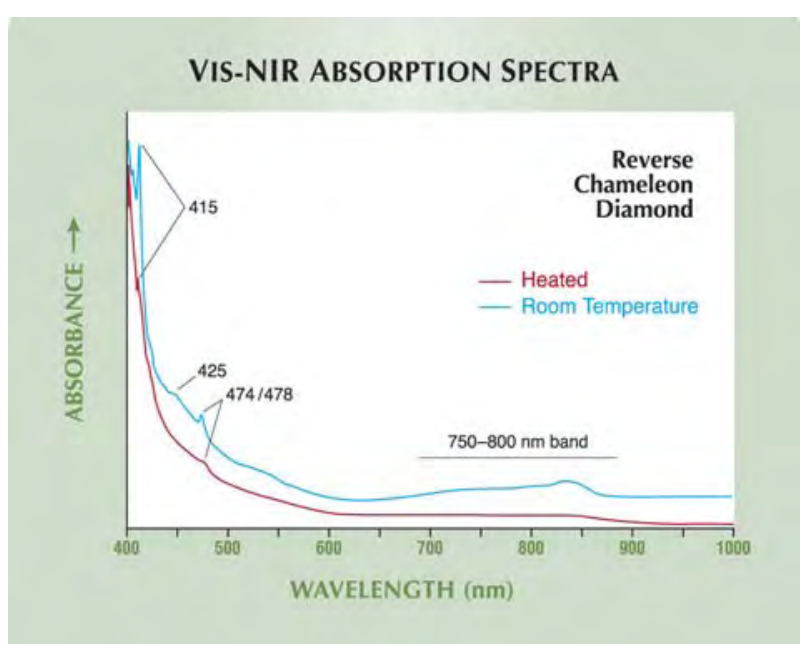


Spectra taken at temperatures of $150-350^{\circ} \mathrm{C}$ (i.e., with a stone exhibiting its unstable color) revealed a weakening of all the above-mentioned absorption features. There was also a general decrease in transmittance in the blue and, particularly, green regions of the spectrum (again, see figure 10). This behavior was reported previously by Fritsch et al. (1995).

In addition to the hydrogen-related features recorded in the infrared spectra (e.g., at 3107 and 1405 $\mathrm{cm}^{-1}$, evidence of hydrogen was found in the visible range as the $425 \mathrm{~nm}$ absorption, which always occurred together with the $480 \mathrm{~nm}$ band. The 480 $\mathrm{nm}$ band is known from type $\mathrm{Ib} / \mathrm{aA}$ diamonds of orange to orangy yellow color (Field, 1992; Zaitsev, 2001, p. 296). In the experience of the authors, hydrogen-related bands are known mainly from the spectra of grayish green to grayish yellow diamonds. A comparison of these spectra with that of a Classic chameleon diamond can be seen in figure 11 .

Reverse Group. Diamonds from this group showed strong N3 and N2 centers, with absorptions between 415 and $478 \mathrm{~nm}$ ("cape lines") and a broad asymmetric band in the $650-900 \mathrm{~nm}$ region that was centered at $750-800 \mathrm{~nm}$ (figure 12). The differences between the spectra of heated and ambienttemperature stones were not always very distinct. All of the absorption features commonly weakened on heating (again, see figure 12).
Photoluminescence Spectroscopy. Again, two different groups of spectra were obtained, corresponding to the Classic and Reverse groups (figures 13 and 14). While the spectra differed considerably between the two groups, they also had some peaks in common, such as a strong emission at $701 \mathrm{~nm}$. The Classic group exhibited a total of 44 PL emissions between 554 and $949 \mathrm{~nm}$, versus 20 emissions for the Reverse group.

Classic Group. The broadband emission of the Classic group chameleon diamonds occurred mainly as one band centered at $630-650 \mathrm{~nm}$; a weak band centered at $730 \mathrm{~nm}$ also was usually visible, which is caused by the vibronic structure of the 701 $\mathrm{nm}$ center (Iakoubovskii and Adriaenssens, 2001). The color of this luminescence induced by the 532 $\mathrm{nm}$ laser is equivalent to reddish orange or orangy red. In the experience of the authors, this broadband emission is similar to the one exhibited by type $\mathrm{IaA} / \mathrm{Ib}$ orange to orangy yellow diamonds that exhibit the $480 \mathrm{~nm}$ band (figure 15), which is consistent with the comparison seen in figure 11 .

The chameleon diamonds of the Classic group (figure 13) were characterized mainly by usually strong emissions at 590 and $595 \mathrm{~nm}$, sometimes a weak to strong peak at $701 \mathrm{~nm}$ with associated vibronic sidebands at 716 and $726 \mathrm{~nm}$ (Iakoubovskii and Adriaenssens, 2001), and several weaker but

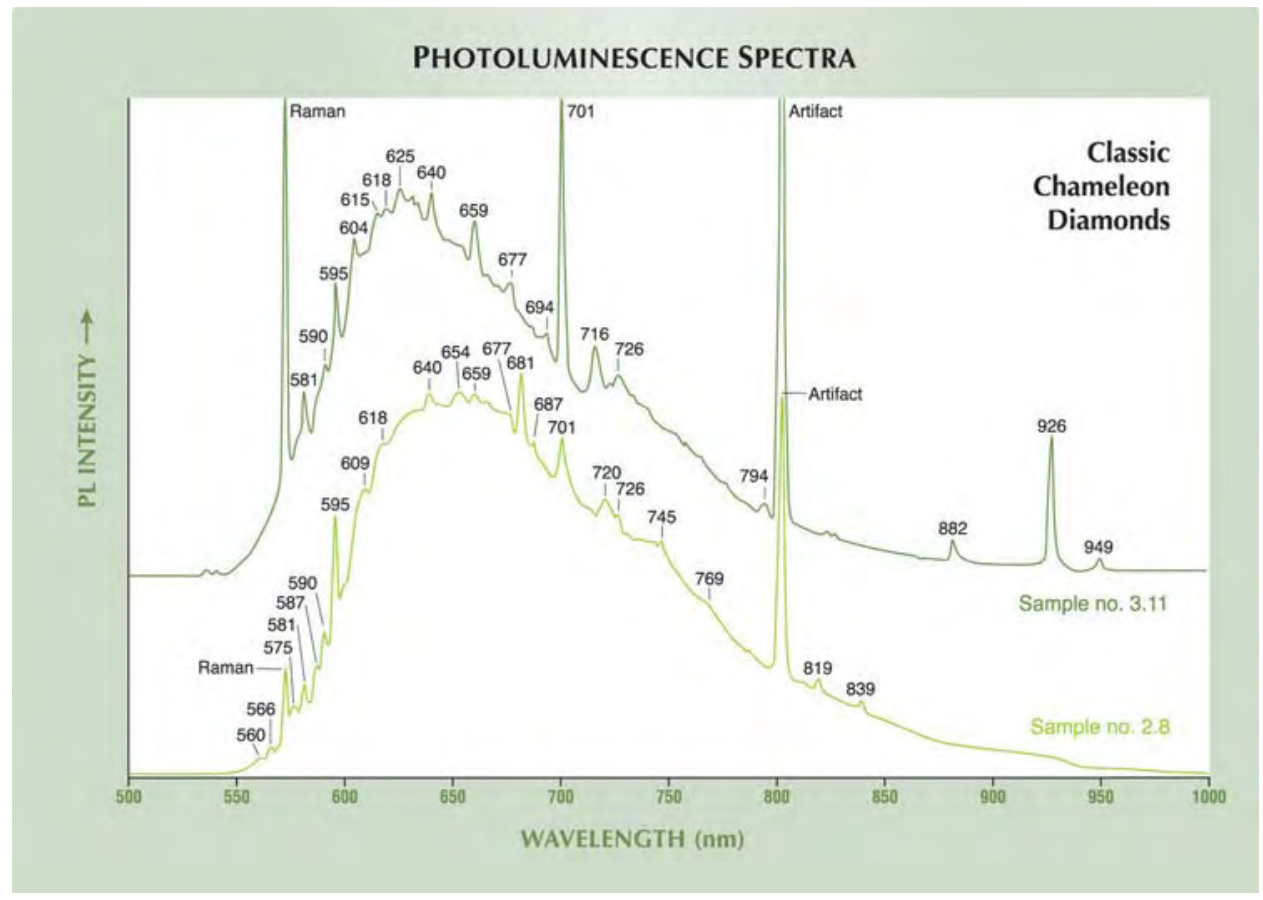

Figure 13. Typical PL spectra for Classic chameleon diamonds are shown here. The peaks in the NIR region between 700 and 950 $\mathrm{nm}$ are characteristic. The spectra have been shifted vertically for clarity. 


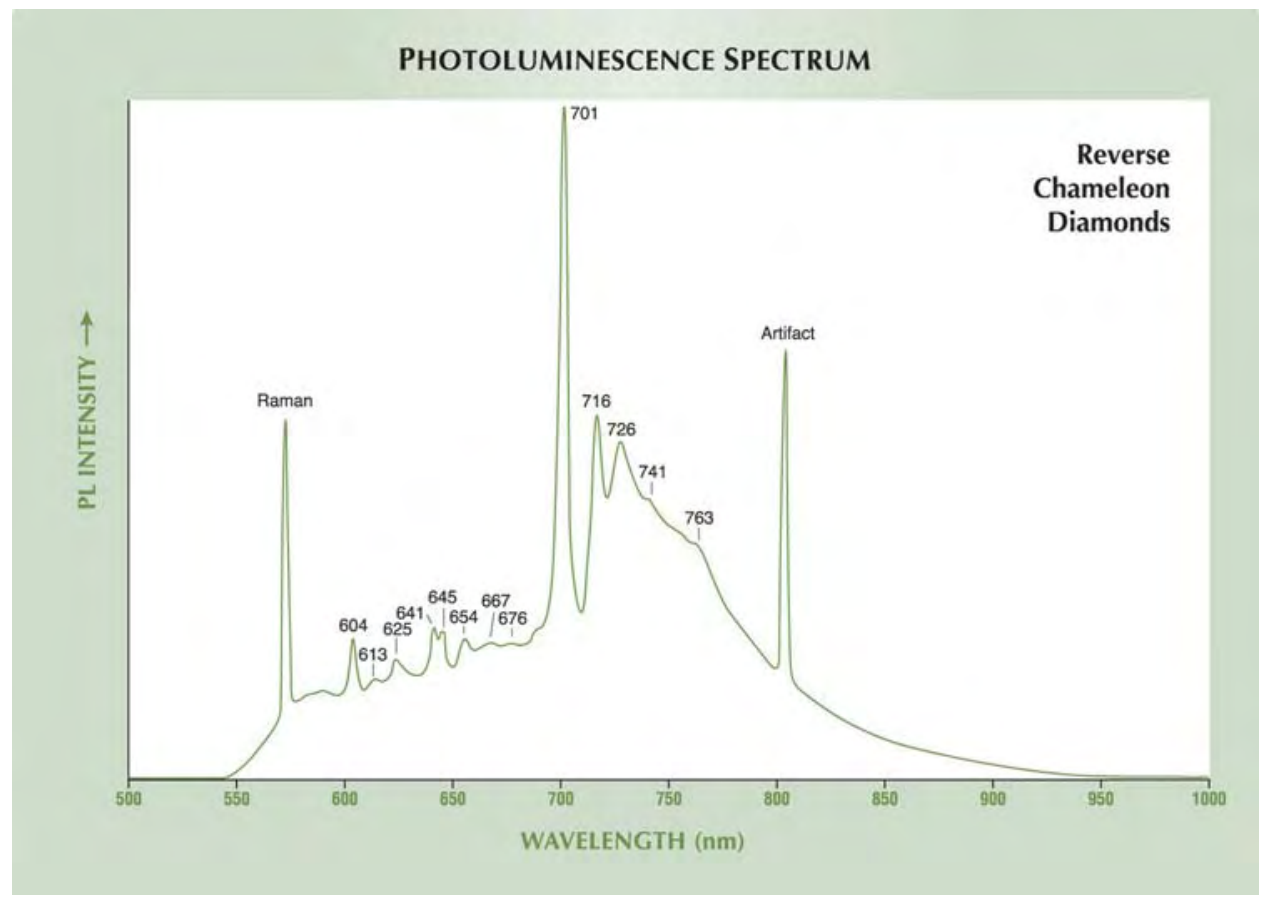

Figure 14. This PL spectrum is typical for a chameleon diamond of the Reverse group (sample 4.5) is shown here. Characteristic features include the peak at 604 nm, the dominant 701 $n m$ center, the doublet at $641 / 645 \mathrm{~nm}$, and the GR1 peak at $741 \mathrm{~nm}$.

very characteristic peaks in the NIR region of the PL spectrum, at 769, 794, 800, 819, 839, 882, 926, and $949 \mathrm{~nm}$.

Reverse Group. For the Reverse group, PL variations from stone to stone were minor (figure 14). These diamonds had luminescence spectra that basically consisted of one large, sloping plateaulike structure comprised of multiple bands between 580 and $800 \mathrm{~nm}$. The luminescence excited by the $532 \mathrm{~nm}$ laser was equivalent to an orange yellow to orange emission.

The PL spectra of the Reverse group samples (figure 14) were characterized mainly by a peak at 604 $\mathrm{nm}$, a doublet at 641 and $645 \mathrm{~nm}$, and a strong to very strong emission at $701 \mathrm{~nm}$ with vibronic sidebands at 716 and $726 \mathrm{~nm}$ (Iakoubovskii and Adriaenssens, 2001). The PL peaks in the NIR region of the Classic samples were not present in the spectra of the Reverse chameleons, except for the $926 \mathrm{~nm}$ feature, which was detected in the spectra of two samples. Most of the Reverse group diamonds showed a very weak $741 \mathrm{~nm}$ GR1 peak and a weak feature at $763 \mathrm{~nm}$.

\section{DISCUSSION}

Analysis of the Vis-NIR absorption spectra of the chameleon diamonds confirms that the transmission window between the two broad bands at 480 and $800 \mathrm{~nm}$ is responsible for the green color of the Classic group (Fritsch et al., 1995). On heating, the
$480 \mathrm{~nm}$ absorption is slightly reduced and the 800 $\mathrm{nm}$ band practically disappears, which explains the change in color (Fritsch et al., 1995). The $800 \mathrm{~nm}$ band is very broad and ranges all the way from about 575 to $1000 \mathrm{~nm}$; thus, it absorbs from the red all the way to the yellow region. Therefore, there is a transmission window centered at about $560 \mathrm{~nm}$, which is shifted toward the red and yellow regions on heating. The $480 \mathrm{~nm}$ band absorbs slightly in the blue and accentuates the transmission window at $560 \mathrm{~nm}$ in the green. Unfortunately, UV-Vis absorption spectroscopy at room and elevated temperatures did not record any features consistent with a change to a greener color in the Reverse group. Further work is needed to establish the cause of this color modification. The reduction of the bands centered at $750-800 \mathrm{~nm}$ would only explain a yellower color, but not a greener hue. A luminescence effect can be excluded, since no green transmission luminescence was observed in the Reverse chameleon diamonds, regardless of temperature.

The long-lasting phosphorescence is a very characteristic feature of chameleon diamonds. Conversely, the authors have noted a lack of phosphorescence in samples of yellow to "olive" hydrogen-containing diamonds with spectral properties similar to chameleons, but lacking any chameleon behavior.

The Reverse chameleons contain more nitrogen and hydrogen than the stones from the Classic group. There is a known correlation in diamond between the presence of hydrogen and relatively 


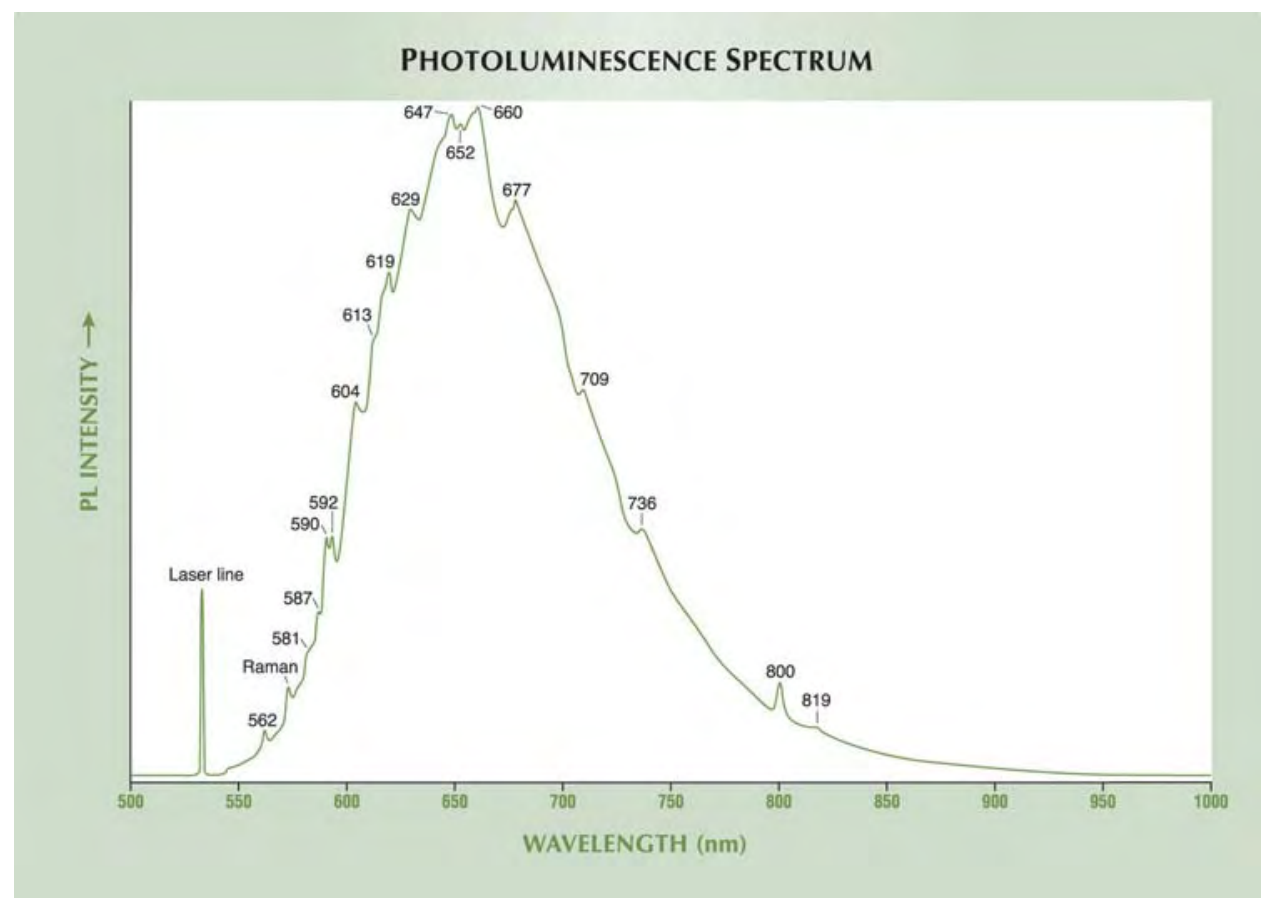

Figure 15. In this PL spectrum of a natural yellow-orange diamond colored by the $480 \mathrm{~nm}$ band, the broadband emission is very similar to the one observed in the Classic chameleon diamonds.

large amounts of nitrogen (Iakoubovskii and Adriaenssens, 2001; Rondeau et al., 2004); therefore, any $\mathrm{H}$-rich diamond will be $\mathrm{N}$-rich as well. As expected, Reverse chameleons show more distinct absorptions related to their hydrogen-rich character, in particular in the visible range, with bands of the "yellow-gray to violet to brown family," for example, at 563 and $474 \mathrm{~nm}$ (Fritsch et al., 1991). Although no definite proof exists that these absorptions are due to a defect containing hydrogen, the authors can confirm that all these absorptions are exclusively present in hydrogen-rich diamonds and are therefore hydrogen-related. The absorption complex between approximately 600 and $900 \mathrm{~nm}$, with apparent maxima in the range of $820-860 \mathrm{~nm}$ (not seen in Classic chameleons) is also probably $\mathrm{H}$ related (see figure 11). Therefore, the change in color seen in the Reverse chameleon diamonds, mostly explained by the reduction in these bands at around $140^{\circ} \mathrm{C}$ and above, is clearly related to the presence of hydrogen. The exact atomic-scale nature of these defects is unknown at present.

In the infrared range, the $\mathrm{C}-\mathrm{H}$ related absorptions in H-rich diamonds have been described by Fritsch et al. (1991), as well as by Woods and Collins (1983), and have been recently reviewed by DeWeerdt et al. (2003) and Rondeau et al. (2004). In the chameleon diamonds studied here, no correlation was found between the strength of the color change and the amount of the IR-active hydrogen. On the contrary, yellow to "olive" diamonds with very high hydrogen content usually exhibit no chameleon behavior
(Hainschwang, 2004). "Olive" diamonds colored by plastic deformation do not show a chameleon behavior, either. However, such stones do clearly show different color distribution in the form of colored graining along octahedral slip planes (Hainschwang, 2003). The infrared spectra of such "olive" type IaA and Ib stones exhibit amber center absorptions (Du Preez, 1965), typically with the main feature being a double peak at 4165 and 4065 $\mathrm{cm}^{-1}$ (Hainschwang, 2003; Massi, 2003). Previous work has demonstrated that in strongly zoned Classic chameleons, the more intensely colored zones are richer in hydrogen; thus, at least the intensity of color appears to be hydrogen-related (F. Notari, pers. comm., 2004).

The presence of the $1495 \mathrm{~cm}^{-1}$ absorption seems to imply that Reverse chameleons have undergone irradiation and annealing (Zaitsev, 2001, p. 44) in nature, unlike the Classic ones. This natural irradiation is confirmed by the presence of a weak GR1 emission at $741 \mathrm{~nm}$ in the PL spectra of most Reverse chameleons.

The $1430 \mathrm{~cm}^{-1}$ absorptions seen in both groups appear to be different: In the Classic chameleons, the observed range of positions between 1434 and $1428 \mathrm{~cm}^{-1}$, the band width of 25 to $35 \mathrm{~cm}^{-1}$, and the missing correlation with the platelet peak indicate that this absorption is not the same as the $1430 \mathrm{~cm}^{-1}$ absorption described by Woods (1986). This is in fact the first report of this feature. In contrast, the sharp $1430 \mathrm{~cm}^{-1}$ absorption in the Reverse chameleons correlates well with the 


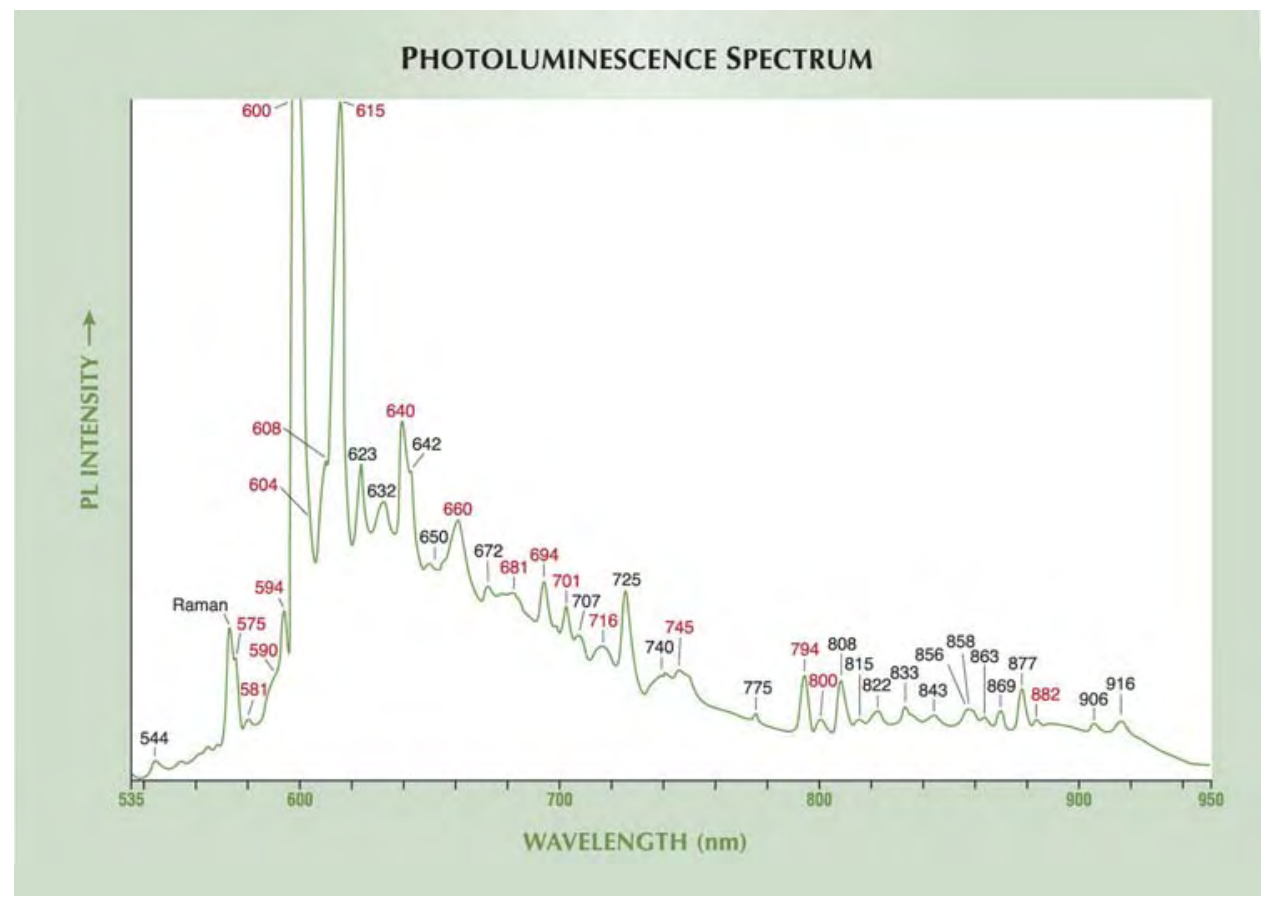

Figure 16. In this PL spectrum of a Ni-rich HPHT-treated synthetic diamond, the emissions in the NIR region are typical for Ni-related defects. There are many similarities to the features seen in Classic chameleon diamonds; identical peak positions are marked in red.

platelet peak and thus clearly points toward the feature published by Woods (1986).

The Classic chameleon category shows two absorptions (at 1590-1577 and 1548-1544 $\mathrm{cm}^{-1}$ ) that may correspond to those reported at 1580 and 1544 $\mathrm{cm}^{-1}$ by Collins and Mohammed (1982) in natural brown diamonds. Interestingly, the somewhat broad $1434-1428 \mathrm{~cm}^{-1}$ feature was only present together with the $1548-1544 \mathrm{~cm}^{-1}$ and $1590-1577 \mathrm{~cm}^{-1}$ absorptions; none of them occurred as isolated features. Even though these absorptions were found only in the Classic chameleon diamonds, which were richer in hydrogen, a direct correlation between them and the hydrogen content could not be established with certainty. Nevertheless, our observations indicate that these absorptions may tentatively be assigned to a hydrogen-related defect. The features at $1546,1543,1518$, and $1500 \mathrm{~cm}^{-1}$ seen in the Reverse chameleons have been described by Iakoubovskii and Adriaenssens (2001) and Hainschwang (2004) in hydrogen-rich diamonds. The absorptions at 1577 and $1546 \mathrm{~cm}^{-1}$ seem to be the same as those seen in the Classic chameleons.

Emissions at 581 and $596 \mathrm{~nm}$ detectable by PL spectroscopy have been reported previously, for diamonds with yellow luminescence (Zaitsev, 2001, pp. $212,216)$ to long-wave UV. They are absent in Reverse chameleons, which primarily luminesce blue to long-wave UV. The vibronic structure of the $701 \mathrm{~nm}$ center (with its sidebands at 716 and $726 \mathrm{~nm}$ ) was identified by Iakoubovskii and Adriaenssens (2001) as probably nickel-related. The 794 nm emis- sion seen in the PL spectra of many Classic chameleon diamonds is interpreted as a nickel-nitrogen defect that has been documented in synthetic and certain natural diamonds (Lawson and Kanda, 1993). A distinct doublet at 883 and $884 \mathrm{~nm}$ found in synthetic diamonds grown by the temperature-gradient method with a Ni catalyst was assigned to a nickel defect (Lawson and Kanda, 1993); in certain samples, a single peak at $882 \mathrm{~nm}$ was found instead (figure 16). The peak observed in the Classic chameleon diamonds at $882 \mathrm{~nm}$ can most probably be assigned to the same or a similar Ni-related defect.

The $926 \mathrm{~nm}$ PL peak in the Classic (and rarely also the Reverse) chameleon diamonds has been recorded by one of us (TH) in some hydrogen-rich violet-blue-gray and "straw" yellow diamonds, as well as in one HPHT-treated yellow diamond that was originally olive-brown. In this diamond, the $926 \mathrm{~nm}$ peak (absent before treatment) was created during the HPHT process $\left(2000^{\circ} \mathrm{C}\right.$ at $65 \mathrm{kbar}$ for 10 minutes). Interestingly, it was produced together with a vibronic system, yielding peaks at 701, 716, and $726 \mathrm{~nm}$ (Hainschwang et al., 2005). The tentative assignment of the $701 \mathrm{~nm}$ center to a Ni-related defect by Iakoubovskii and Adriaenssens (2001) leads to the possible attribution of these apparently related features to a nickel-nitrogen defect. This is due to the fact that a defect created by the annealing of a "normal" type Ia diamond most probably involves nitrogen. Assuming that this is a nickel defect as proposed by the above authors, its creation by annealing indicates a nickel- 
nitrogen complex for the defects at 701 and $926 \mathrm{~nm}$.

Most of the other sharp bands in the PL spectra of Classic chameleon diamonds also have been observed in natural brown diamonds (Smith et al., 2000; Zaitsev, 2001; Hainschwang, 2003), and the ones seen in the Reverse chameleons are seen in hydrogen-rich diamonds from the Argyle mine (Iakoubovskii and Adriaenssens, 2001). The defects responsible for most of these emissions are unknown. Many of the PL emissions shown by Classic chameleons are reminiscent of those seen in synthetic diamonds grown with a Ni catalyst; such stones characteristically show multiple emissions in the NIR range (figure 16).

The presence of $\mathrm{Ni}$ in the Classic and the Reverse chameleons as indicated by PL spectroscopy was recently confirmed by one of us (TH) using EDXRF chemical analysis: two Reverse and two Classic chameleons were analyzed and all of them exhibited rather distinct $\mathrm{Ni}$ peaks.

The observation of a color change solely induced by relatively low heat in the Reverse chameleons indicates that a thermochromic color change can be caused by a hydrogen-related defect. The photochromic color change induced by storage in the dark is unique to the Classic chameleon diamonds. Three factors may be involved in the combined thermochromic and photochromic chameleon behavior of the Classic group: the implied weak type Ib character, a specific (although unknown) hydrogen-related defect, and possibly the presence of $\mathrm{Ni}$.

The Classic and Reverse groups are related to some degree and do have significant properties in common. However, the fact that the Reverse group lacks a photochromic color change and exhibits only a weak-to-distinct thermochromic color change raises the question as to whether such solely thermochromic diamonds should be called chameleon diamonds, or whether this name should be reserved for diamonds exhibiting both thermochromic and photochromic color change. Presently, the GIA Gem Laboratory only recognizes diamonds in the latter, "Classic" group as chameleons.

\section{CONCLUSIONS}

This study has differentiated two sample groups from a collection of 39 chameleon diamonds: those showing only thermochromic color change and those that exhibit both thermochromic and photochromic behavior. Each group exhibited distinctive hue changes. We propose the term Classic for those that show the green-to-yellow behavior with heating or after prolonged storage in the dark; this color change is commonly associated with chameleon diamonds. Those that lack a photochromic color change- that is, they become slightly greener and more saturated only when heated-are here called Reverse chameleons.

The presence of the $480 \mathrm{~nm}$ band and hydrogenrelated features such as the $425 \mathrm{~nm}$ absorption suggests that Classic chameleon diamonds fall between very hydrogen-rich diamonds and type IaA/Ib diamonds that exhibit the $480 \mathrm{~nm}$ absorption band (figure 11). This is also strongly indicated by the fact that some truly hydrogen-rich diamonds such as the Reverse chameleons exhibit this "low temperature" (i.e., below $200^{\circ} \mathrm{C}$ ) thermochromic color change. This is further confirmed by comparison of the PL spectra of Classic chameleons and those of type $\mathrm{Ib} / \mathrm{aA}$ orange diamonds that exhibit the $480 \mathrm{~nm}$ band (again, see figures 13 and 15). Hydrogen-rich diamonds very frequently exhibit PL spectra reminiscent of those of the Reverse chameleons (Hainschwang, 2001; Iakoubovskii and Adriaenssens, 2001). The influence and role of single nitrogen and the $480 \mathrm{~nm}$ band in the color change of the Classic chameleon diamonds will be the subject of future research by the authors.

We have shown that the easiest way to identify chameleon diamonds is by heating them to moderate temperature and observing the change in color. However, this study proved that the Classic chameleon diamonds also could be identified by a combination of their spectroscopic properties and their reaction to UV radiation. This is preferable to heating, to avoid modifying the color of green diamonds that are not chameleons; their radiationcaused coloration is rather sensitive to heat and in some cases absorptions in the visible range are known to be modified at emperatures as low as $275^{\circ} \mathrm{C}$ (see, e.g., Collins et al., 1988). All of the chameleon diamonds exhibited yellow phosphorescence after exposoure to short-wave UV. The absence of this yellow afterglow in any hydrogen-containing yellow to "olive" diamond indicates that no chameleon effect will be present. Also, in the experience of the authors, stones that lack traces of hydrogen in their IR spectra and stones that show ambercenter absorption were never found to exhibit this unusual change in color (see e.g., Hainschwang, 2003). The Reverse chameleon diamonds cannot always be identified without heating, but since yellow diamonds are not permanently modified by 
simple heating at relatively low temperature, the heating test is not problematic for such samples.

The presence of hydrogen and nickel in these diamonds has been demonstrated by various spectroscopic methods; emissions assigned to $\mathrm{Ni}$ impurities were identified particularly in the Classic group by PL spectroscopy.

At present, we can only speculate about the cause of the color change in Classic chameleon diamonds.
The results presented here point toward a defect involving hydrogen combined with the $480 \mathrm{~nm}$ band, which is related to isolated single nitorgen atoms. This combination seems to cause the themochromic and photochromic change in color; whether $\mathrm{Ni}$ plays a role in this color change remains to be seen. In the diamonds exhibiting only a thermochromic color change, such as the Reverse chamelons, the defects appear to be solely hydrogen-related.
ABOUT THE AUTHORS

Mr. Hainschwang (thomas.hainschwang@gia.edu) is research gemologist at GIA's GemTechLab in Geneva, Switzerland; he performed the research for this article prior to joining GIA, while he was director of Gemlab Gemological Laboratory in Liechtenstein. Mr. Simic is a gemologist at EGL USA, New York. Dr. Fritsch is professor at the University of Nantes, Institut des Matériaux Jean Rouxel (IMN-CNRS), Nantes, France. Mr. Deljanin is director of research and director of Canadian operations for the EGL USA group, Vancouver, British Columbia, Canada. Ms. Woodring is a gemologist and educational instructor, and Mr. DelRe is manager of Gemological Services, at EGL USA, New York.

ACKNOWLEDGMENTS: The authors are grateful to Nilesh Sheth of Nice Diamonds, New York, a subsidiary of Forever Collections Inc., for loaning the "Forever Chameleon Collection" for this research, and to Franck Notari, Director of GemTechLab, for fruitful discussions.

\section{REFERENCES}

Collins A.T., Mohammed K. (1982) Optical studies of vibronic bands in yellow luminescing natural diamonds. Journal of Physics C, Vol. 15, No. 1, pp. 147-158.

Collins A.T., Szechi J., Tavender S. (1988) Resonant excitation of the GR centre in diamond. Journal of Physics C, Vol. 21, No. 7, pp. L161-L164.

Chabert V., Reinitz I. (2000) Gem Trade Lab Notes: Diamondchameleon, with blue-to-violet "transmission" luminescence. Gems « Gemology, Vol. 36, No. 1, pp. 60-61.

Deljanin B. (2004) Lab Notes: Chameleon diamonds. Canadian Diamonds, Summer, pp. 24-25.

DeWeerdt F., Pal'yanov Y.N., Collins A.T. (2003). Absorption spectra of hydrogen in ${ }^{13} \mathrm{C}$ diamond produced by high-pressure, high-temperature synthesis. Journal of Physics: Condensed Matter, Vol. 15, No. 19, pp. 3163-3170.

Du Preez L. (1965) Paramagnetic resonance and optical investigations of defect centres in diamond. Ph.D. dissertation, University of the Witwatersrand, Johannesburg, South Africa, pp. 83-84.

Field J.E., Ed. (1992) The Properties of Natural and Synthetic Diamond. Academic Press, London.

Fritsch E., Scarratt K., Collins A.T. (1991) Optical properties of diamonds with an unusually high hydrogen content. In R. Messier, J.T. Glass, J.E. Butler, R. Roy, Eds., Materials Research Society International Conference Proceedings, Second International Conference on New Diamond Science and Technology, Washington D.C., Sept. 23-27, Materials Research Society, Pittsburgh, PA, pp. 671-676.

Fritsch E., Shigley J.E., Moses T., Rossman G.R., Zucker B., Balfour I. (1995) Examination of the twenty-two carat green chameleon diamond. In D.J. Content, Ed., A Green Diamond: A Study of Chameleonism, W. S. Maney \& Son, Leeds, England, $42 \mathrm{pp}$.

GIA Diamond Dictionary, 3rd ed. (1993) Gemological Institute of America, Santa Monica, CA, p. 44.

Hainschwang T. (2001) Characterization of hydrogen rich diamonds from Argyle/Australia with Vis/NIR-and photoluminescence-spectroscopy. http://www.gemlab.net/research1_1.htm [accessed 02/18/05].

Hainschwang T. (2003) Classification and color origin of brown diamonds. Diplôme d'Université de Gemmologie, University of Nantes, France.

Hainschwang T. (2004) Gem News International: A diamond exhibiting a spectacular phantom. Gems ↔) Gemology, Vol. 40 , No. 1 , pp. $76-78$.

Hainschwang T., Katrusha A., Vollstaedt H. (2005) HPHT treatment of different classes of type I brown diamonds. Journal of Gemmology, Vol. 29 (in press).

Iakoubovskii K., Adriaenssens G.J. (2001) Optical characterization of natural Argyle diamonds. Diamond and Related Materials, Vol. 11, No. 1, pp. 125-131.

Lawson S.C., Kanda H. (1993) An annealing study of nickel point defects in high-pressure synthetic diamond. Journal of Applied Physics, Vol. 73, No. 8, pp. 3967-3973.

Massi L. (2003) Défauts résponsables de la couleur brune dans les diamants. Mémoire de stage du Diplôme d'Études Approfondies, Sciences des Matériaux, University of Nantes, France.

Rondeau B., Fritsch E., Guiraud M., Chalain J.P., Notari F. (2004) Three historical "asteriated" hydrogen-rich diamonds: Growth history and sector-dependent impurity incorporation. Diamond and Related Materials, Vol. 13, No. 9, pp. $1658-1673$.

Raal F.A. (1969) Mineralogical notes: A study of some gold mine diamonds. American Mineralogist, Vol. 54, Nos. 1-2, pp. 292-295.

Shigley J., Wang W., Moses T., Hall M. (2004) Photoluminescence features of "chameleon" diamonds. Proceedings of the 55th De Beers Diamond Conference, Coventry, England, pp. 4.1-4.2.

Smith C.P., Bosshart G., Ponahlo J., Hammer V.M.F., Klapper H., Schmetzer K. (2000) GE POL diamonds: Before and after. Gems Æ) Gemology, Vol. 36, No. 3, pp. 192-215.

Woods G.S., Collins A.T. (1983) Infrared absorption spectra of hydrogen complexes in type I diamonds. Journal of Physics and Chemistry of Solids, Vol. 44, No. 5, pp. 471-475.

Woods G.S. (1986) Platelets and the infrared absorption of type I diamonds. Proceedings of the Royal Society of London A, Vol. 407, pp. 219-238.

Zaitsev A.M. (2001) Optical Properties of Diamond: A data Handbook. Springer, Berlin, pp. 44, 45, 190-230, 212, 216, 296. 
exceptional quality, rarity, or other attributes). Such specimens are found not only in museums but also in private collections.

The main criteria that determine the uniqueness of gemstones are: (1) aesthetic appeal, (2) purity (i.e., the number and nature of associated minerals) and perfection, (3) rarity, (4) historical importance, and (5) scientific significance. Based on these criteria, several categories of unique stones were recognized, their parameters tabulated, and valuations applied. Particularly unique samples are extremely difficult to value but, as a generalization, their price depends on size, purity, abundance and location of physical defects, availability of details on their geologic occurrence, and publications (scientific or popular) related to the particular specimen.

$B M S$

Managing the commons: An economic approach to pearl industry regulation. $\mathrm{B}$. Poirine, Aquaculture Economics ↔) Management, Vol. 7, No. 3-4, 2003, pp. 179-193.

Unregulated use of tropical lagoons for pearl culture has created problems associated with overexploitation, which has led to declining profits (or losses) for pearl farmers. Various factors cause cultured pearl production to decline and oyster mortality to increase when a critical density is reached. Particular emphasis is placed on the problems facing the Tahitian black cultured pearl industry.

In lagoons owned privately by a single producer, overcrowding is not a problem because profits are maximized far below the critical density. However, in public lagoons, the author proposes that the government should regulate, by auction, the use by a single producer for a specific period of time, with rules to ensure equitable policies toward all producers. Arguments are also made for a global cultured pearl production quota to keep prices from falling due to excess supplies; both Australia and Japan have enacted successful oyster quota policies that have prevented overexploitation and the economic havoc that results from such practices.

$R S$

Not forever: Botswana, conflict diamonds and the Bushmen. I. Taylor and G. Mokhawa, African Affairs, Vol. 102, No. 407, 2003, pp. 261-283.

Although Botswana, a peaceful democracy in southern Africa, has not been implicated in the campaigns against conflict diamonds, the policies of its government regarding tribes of Bushmen living in the Central Kalahari Game Reserve have come under fire.

Botswana is the world's largest diamond producer by value, and diamonds are responsible for $87 \%$ of its foreign exchange. The country, one of the poorest at independence in 1966, is now in the upper-middle income category (with a per capita Gross Domestic Product of more than $\$ 6,000)$, though the distribution of wealth remains very unequal. Because the country is so depen- dent on diamond revenues, its government launched a "Diamonds for Development" campaign to ensure differentiation from other African nations beset by wars that spawned the conflict diamond campaigns. However, a number of nongovernmental organizations (Survival International, in particular) have sought to link the government's policy of removing Bushmen tribes, known as the San, from the Reserve to diamond exploration efforts in that area.

The government cut off services, including water, to the area in January 2002 as part of a policy to resettle the San, claiming the action and the resettlements were to protect wildlife and foster tourism in the area. Survival International drew De Beers-a 50/50 partner in Bostswana's diamond mining operations-into the controversy, as De Beers holds an exploration license near the affected area. De Beers has distanced itself from the government's resettlement policy and noted that its exploration area comprises only $20 \mathrm{~km}^{2}$ of the Reserve's 55,000 $\mathrm{km}^{2}$. Survival International continues to organize protests against. De Beers and the Botswana government.

$R S$

Strategies for sustainable development of the small-scale gold and diamond mining industry of Ghana. R. K.

Amankwah and C. Anim-Sackey, Resources Policy, Vol. 29, No. 3-4, 2003, pp. 131-138.

Small-scale mining of gold and diamonds has helped create employment and government revenue in Ghana. Since the government instituted reforms in 1989 that legalized such activites, more than 1.5 million ounces of gold and 8 million carats of diamonds have been produced. The smallScale Mining Law inlcudes a technical assistance program that has helped with prospecting and development, legalized the purchase of mercury for gold recovery, and established a marketing authority to buy and export gold and diamonds. By the end of 2001, 420 small-scale mining concessions (nine for diamonds) had been licensed. These companies have generated employment for more than 100,000 people.

However, there are still thousands of illegal miners, called galamsey in local parlance, who have created problems for the government. First, conflicts have arisen over their encroachment on concessions held by larger mining companies. some large firms have accommodated the illegal miners by ceding less-economic areas of their concession to them-in exchange for their registering with the government. Second, these illegal miners-and some legal mining enterprises-also cause a great deal of enviornmental damage. Mercury poisoning is a particular problem in some mining villages.

The government has launched an education program to promote cleaner, safer extraction methods. It also has encouraged the formation of small-scale mining associations to better regulate safe and productive mining practices.

$R S$ 